\title{
Functions and Composition Variations of Wheat Glutenin Proteins in Steamed Bread and Noodles
}

\author{
Weiwei Guo ${ }^{1, \dagger}$, Xiaofan Han ${ }^{1, \dagger}$, Zihan $\mathrm{He}^{1}$, Tong Qi ${ }^{1}$, Jiayi Han ${ }^{1} \&$ Yumei Zhang ${ }^{1}$ \\ ${ }^{1}$ Shandong Provincial Key Laboratory of Dryland Farming Technology, College of Agronomy, Qingdao \\ Agricultural University, Qingdao, Shandong, China \\ Correspondence: Yumei Zhang, Shandong Provincial Key Laboratory of Dryland Farming Technology, College \\ of Agronomy, Qingdao Agricultural University, Qingdao, Shandong 266109, China. Tel: 86-532-5895-7446. \\ E-mail: zhangcui2003@163.com
}

$\begin{array}{ll}\text { Received: October 7, } 2021 & \text { Accepted: November 6, } 2021 \quad \text { Online Published: December 15, } 2021 \\ \text { doi:10.5539/jas.v14n1p31 } & \text { URL: https://doi.org/10.5539/jas.v14n1p31 }\end{array}$

$\dagger$ These authors contribute equally to this research.

\begin{abstract}
As a major food crop, wheat offers indispensable energy and nutrients to humans worldwide. With the living standards rising, the demand of high-quality wheat increases sharply. Wheat gluten proteins (glutenins and gliadins) are important components of seed storage proteins that affect the elasticity, strength or viscosity of dough. In this review, we summarize the composition of glutenin subunits in wheat grain and analyze the impact of glutenin on the traditional Chinese foods: steamed bread and noodles. Furthermore, we summarize the molecular markers used for wheat quality breeding. The advent of the recent wheat genomic will speed up the identification and quality breeding of novel glutenins.
\end{abstract}

Keywords: wheat, glutenins, food quality, traditional Chinese foods

\section{The Composition of the Glutenin Subunits in Wheat Grain}

Hexaploid wheat (Triticum aestivum L.), one of the most widely cultivated crops, provides about $20 \%$ calories and proteins to human daily diets (Wang et al., 2020). With the increasing world population, food production need to increase by at least $50 \%$ by 2050 to meet the huge consumption (FAO, 2017). Meanwhile, because of rising living standards, more and more healthy foods with good qualities are demanded. Thus, substantial efforts were needed for improving the yield of good-quality wheats. Wheat quality mainly refers to the end-use value of flour, which depends on the properties of seed storage proteins (SSPs), such as the content and composition of gluten proteins (Gao et al., 2021; Rasheed et al., 2014; Wang et al., 2020).

Wheat glutenin is a complex mixture, which can be divided into HMW-GSs (70000-90000 Da) and LMW-GSs (20000-45000 Da), accounting for $\sim 13 \%$ and $\sim 20 \%$ of SSPs, respectively (Ma et al., 2019). There are three general domains in glutenin protein, including a $\beta$-reverse turn and two terminal $\alpha$-helix domains. More $\beta$-reverse turn structures are considered to be beneficial for wheat flour quality (Ma et al., 2019; Patil et al., 2015; Tilley et al., 2001). HMW-GSs could explain up to $70 \%$ of the genetic variations in dough processing quality, but only makes up about $10 \%$ of gluten proteins (Liu et al., 2005). Six HMW-GS genes are located on the long arms of homoeologous chromosomes $1 \mathrm{~A}, 1 \mathrm{~B}$ and $1 \mathrm{D}$, and each locus has two tightly linked genes that encodes X-and Y-type subunits, namely, TaGlu-1Ax, TaGlu-1Ay, TaGlu-1Bx, TaGlu-1By, TaGlu-1Dx, and TaGlu-1Dy (Galili \& Feldman, 1985) (Figure 1). Due to gene silencing, there are always three to five HMW-GSs in hexaploid wheat (Payne et al., 1981), but in some wild wheat lines diploid (AA) and tetraploid (AABB) 1Ay subunit could express (Hu et al. 2008; Xu et al. 2009). 


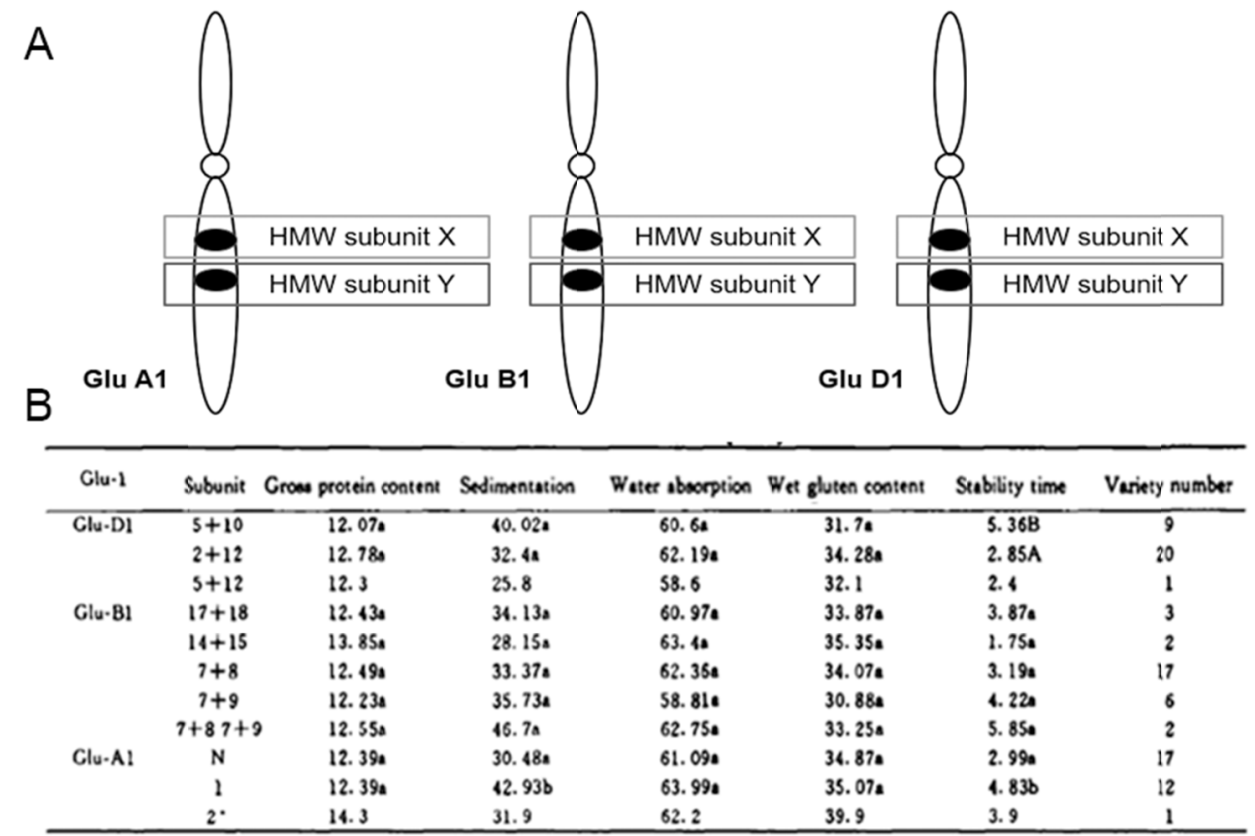

Figure 1. The composition of HMW-GSs. (A) The subunits are split up into three groups: 1A, 1B and 1D; (B) Effect of loci Glu-1 on quality characters (Yang et al., 2003)

LMW-GSs account for about $60 \%$ of the wheat glutenin and are encoded by TaGlu-3 loci on the short arm of homoeologous chromosomes 3A, 3B and 3D (Lee et al., 2016; Lindsay \& Skerritt, 1999). LMW-GS is divided into three-type subunits including LMW-i, LMW-m and LMW-s based on the first amino acid residues of the mature proteins (Clarke et al., 2003; Cloutier et al., 2001). LMW-GS could form intermolecular and intramolecular disulphide bonds because of the eight conserved cysteine residues (Shewry \& Halford, 2002). Previous studies have found that cysteine residues for intermolecular disulphide bonds display an important role in the quality of gluten proteins and are significantly correlated with the properties of dough (Dong et al., 2013; Herpen et al., 2008; Ram et al., 2006).

\section{Wheat Glutenin Variations and Their Roles in Dough Quality}

Variations in amount and composition of wheat gluten account for some variation in properties of dough. In hexaploid wheat, the Glu-A1 locus has been found to have three different subunits, including 1, 2* and Null, which reported that $\mathrm{Ax} 1$ and $\mathrm{Ax} 2 *$ were associated to good bread making quality, while AxNull was responsible for poor quality (Kocourkova et al., 2008; Payne, 1987). Rogers et al. (1997) found that 1 Ay subunit from diploid T. boeoticum Boiss. ssp. thaoudar could increase the gluten strength of hexaploidy wheat. Glu-B1 exhibits the richest variation in $1 \mathrm{Bx}+1 \mathrm{By}$ subunit pairs of hexaploid wheat, such as $1 \mathrm{Bx} 7,1 \mathrm{Bx} 7+1 \mathrm{By} 8,1 \mathrm{Bx} 7$ $+1 \mathrm{By} 9,1 \mathrm{~B} x 6+1 \mathrm{By} 8,1 \mathrm{Bx} 13+1 \mathrm{By} 16,1 \mathrm{Bx} 13+1 \mathrm{By} 19,1 \mathrm{~B} x 14+1 \mathrm{By} 15,1 \mathrm{~B} x 17+1 \mathrm{By} 18,1 \mathrm{~B} x 20$ and $1 \mathrm{By} 20$ (Anjum et al., 2007). 1Bx7 + 1By8, 1Bx7 + 1By9, 1Bx13 + 1By16, $1 \mathrm{~B} x 17+1 \mathrm{By} 18$ and $1 \mathrm{By} 20$ are more common variation types of HMW-GSs at $G l u-B 1$ locus (Hu, 2003). Compared to hexaploid wheat, there were more variations in tetraploid at Glu-B1 locus, and $1 \mathrm{Bx} 6+1 \mathrm{By} 8$ was the most frequent allele in Triticum spelta (Xu et al. 2009). Jondiko et al. (2012) reported that $1 \mathrm{Bx} 7+1 \mathrm{By} 9$ could increase dough strength, and another study found that the recombinant inbred lines (RILs) containing $1 \mathrm{Bx} 7+1 \mathrm{By} 9$ displayed a higher SDSsedimentation volume than that with 1Bx20 at Glu-B1 locus (Jondiko et al., 2012; Nishio et al., 2007). Chen et al. (2019) reported that the absence of $1 \mathrm{Bx} 7+1 \mathrm{By} 9$ could lead to weaker dough strength and inferior sponge cake performance (Chen et al., 2019). The 1Bx14 + 1By15 subunits are beneficial to the accumulation of endosperm in the near-isogenic lines (NILs) with Glu-1Bh (Zhao et al., 2020). The 1Bx17+1By18 subunits are tightly associated with strong dough quality, while $1 \mathrm{~B} \times 20+1 \mathrm{By} 20$ are associated with weak dough (Cornish et al., 2001; Ma et al., 2019). Tang et al. (2008) reported that the subunits $1 \mathrm{Bx} 6+1 \mathrm{By} 8$ from synthetic hexaploid wheat exhibited better overall quality characteristics than $1 \mathrm{Bx} 7+1 \mathrm{By} 8$. Compared to Glu-B1, Glu-D1 locus exhibit less variation, including 1Dx2 + 1Dy12, 1Dx3 + 1Dy12, 1Dx4 + 1Dy12, 1Dx5 + 1Dy10, 1Dx2 + 1Dy10, 1Dx2.2 + 1Dy12 and 1Dx2 + 1Dy11 (Deng et al., 2006). Among these subunits, 1Dx5 + 1Dy10 subunits are usually beneficial to wheat processing quality (Gupta et al., 1994; Lafiandra et al., 1993; Ma et al., 2005; Xu et 
al., 2008). Yanaka et al. (2007) found that the novel allelic locus Glu-Dld at Glu-D1 was positively associated to dough strength. The subunits 1Dx5 + 1Dy10 exhibits more effects on SDS sedimentation value, dough mixing time and dough strength than 1Dx2 + 1Dy12 (Liang et al., 2010). 1Dx5', the same electrophoretic mobility as the traditional one $1 \mathrm{Dx} 5$ in sodium dodecyl sulfate polyacrylamide gel electrophoresis (SDS-PAGE), was identified associated with good baking quality (Feng et al., 2011; Yan et al., 2008). The allele Glu-D1d (1Dx5 + 1Dy10) was found associated with good quality in $1 T$. aestivum ssp. spelta accession, 5 T. aestivum ssp. macha accessions and 7 T. aestivum ssp. compactum accessions (Xu et al. 2009). On the basis of relationship between wheat quality and HMW-GS alleles, several scoring systems have been established for the processing quality's prediction (Wang et al., 2018). Comparing the contribution rates of Glu-1, the decreasing order was: Glu-Dl > Glu-Al > Glu-B1 (Payne et al., 1981). But another study reported that because of the rich variation of Glu-B1 and Glu-D1 locus, the decreasing order was: Glu-D1 > Glu-B1>Glu-A1 (Lawrence et al., 1988). According to quality contributions, the different subunits were ranked as: $1 \mathrm{Ax} 1>1 \mathrm{Ax} 2 *>1 \mathrm{AxNull}$ at Glu-A1 locus, $1 \mathrm{Bx} 14+$ $1 \mathrm{By} 15>1 \mathrm{Bx} 7+1 \mathrm{By} 8>1 \mathrm{Bx} 17+1 \mathrm{By} 18>1 \mathrm{Bx} 7+1 \mathrm{By} 9$ at $\mathrm{Glu}-\mathrm{B} 1$ locus, and 1Dx $5+1 \mathrm{Dy} 10>1 \mathrm{Dx} 2+$ $1 \mathrm{Dy} 12>1 \mathrm{Dx} 4+1 \mathrm{Dy} 12$ at Glu-D1 locus (Gao et al., 2002). Ma et al. (2019) found that the wheat genotypes that had subunits $13+16$ or $7 *+8$ at Glu-B1 locus and $5+10$ at Glu-D1 locus without 1BL/1RS translocation were expected to contain strong-gluten proteins in wheat grain.

As one of the major components of wheat storage proteins, the LMW-GS plays an important role in dough quality in terms of allele variations and expression levels. Dong et al. (2010) found that high expression of LMW-GS in Xiaoyan 54 exhibited better dough quality than Jing 411. There are many kinds of variations in

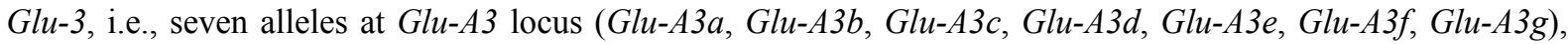
nine alleles at Glu-B3 locus (Glu-B3a, Glu-B3b, Glu-B3c, Glu-D3d, Glu-D3e, Glu-D3f, Glu-D3g, Glu-D3h, Glu-D3i), eleven alleles at Glu-D3 locus (Glu-D3a, Glu-D3b, Glu-D3c, Glu-D3d, Glu-D3e, Glu-D3f, Glu-D3g, Glu-D3h, Glu-D3i, Glu-D3j, Glu-D3k) (Appelbee et al., 2009; Cherdouh et al., 2010). It has been reported that the variation of $G l u-3$ significantly affected wholemeal flour protein content (WFP) and mid-line peak value (MPV) (Luo et al., 2001). Glu-A3g, Glu-A3b and Glu-A3i were found associated with elite dough quality by analyzing the near-isogenic lines (NILs) of the variety Aroona (Zhang et al., 2012). Lee et al. (2016) found that the wheat varieties containing Glu-B3b, Glu-A3d, Glu-B3g and $G l u-B 3 i$ displayed better bread baking quality than Glu-A3e and Glu-B3c. The Glu-A3m and Glu-A1b were more significantly correlated with dough resistance and extensibility than GluA1c and Glu-A3k respectively (Gupta et al., 1989). LMW-N13, a novel LMW-GS identified from Aegilops uniaristata, was found to display superior dough properties (Du et al., 2020). Together, the variations between gluten subunits and dough properties provides useful data for quality breeding in wheat.

\section{Impacts of Glutenin on the Traditional Wheat Food}

Chinese steamed bread and noodles are the most popular products of wheat in the north China. There is about $72 \%$ Chinese wheat used for human consumption (Lin et al., 2020). Previous study indicated that protein content of flour was significantly associated with steamed bread quality (Deng et al., 2007). He et al. (2003) found that extension of extensograph and gluten strength were positively correlated with steamed bread volume and springiness. Liang et al. (2015) showed that the appropriate proportion of strong and weak gluten chose for the high-quality traits of steamed bread and noodles.

Noodles, one of the most popular consumptive styles of wheat, quality is mainly evaluated by color, surface appearance, texture, firmness, cohesiveness and tensile strength (Zhou et al., 2013). Hou et al. (2013) showed that gluten quality was positively correlated with noodles texture. HMW-GS, one of the most important storage protein, plays a key role in the elasticity and strength of gluten (Liu et al., 2009). HMW-GS content and combinations are positively associated with cooking time, hardness, elasticity, cohesiveness and chew ability of noodles (Zhang et al., 2013). Influences of different subunits on noodle quality were $1 \mathrm{AxNull}>1 \mathrm{Ax} 1,1 \mathrm{Bx} 7+$ $1 \mathrm{By} 8>1 \mathrm{Bx} 7+1 \mathrm{By} 9>1 \mathrm{Bx} 14+1 \mathrm{By} 15,1 \mathrm{Dx} 4+1 \mathrm{Dy} 12>1 \mathrm{Dx} 5+1 \mathrm{Dy} 10 \geq 1 \mathrm{Dx} 2+1 \mathrm{Dy} 12$, and the $1 \mathrm{Bx} 7+1 \mathrm{By} 8$ at $G l u-B 1$ locus is the most important subunit for high-quality noodles, while Null/7 + 8/2 + 12, $1 / 7+8 / 4+12$ and $1 / 7+8 / 5+10$ are the recommended combination (Zhang et al., 2013). Nieto et al. (1994) found that the increasing Y-type HMW-GS speed up the improvement of gluten macropolymers and gluten strength. He et al. (2005) selected 158 winter and facultative cultivars for detecting the effects of HMW-GS and LMW-GS on Chinese noodles quality, and the results indicated that $G l u-A 3 d$ and $G l u-B 3 d$ were slightly better for noodles quality. Park et al. (2011) found that Glu3 together with Glu-l was able to improve the quality of cooked noodles. Meanwhile, Tang et al. (2010) found that Glu-B1d $(6+8)$ had a positive influence on Chinese noodles, especially combined with the subunits $G l u-A 1$ and $G l u-D 1$. In order to find the relationship between wheat gluten and the processing quality of Xinjiang hand-stretched noodles (XHSN), 195 wheat varieties were used to analysis, and the results identified that the variation of subunits displayed different effects on the quality of 
XHSN, such as $1,2^{*}, 7+9,17+18,5+10$, gluA3a, gluB3a, gluB3b, gluB3d and gluB3g significantly increased the quality of proteins, but $G l u-A 3 c$ was positively associated with protein amount (Xiang et al., 2015).

Steamed bread is an important staple food in China, and about $40 \%$ of wheat is used for making Chinese steamed bread (He et al., 2003). Steamed bread is generally divided into two types, southern and northern types. There are more studies focusing on northern type steamed bread, because of its popular production. In modern time, steamed bread is usually made by mechanized or semi-mechanized method, which require different flour quality. Zhao et al. (1995) found that the most optimum wheat varieties for cooking steamed bread were middle gluten wheat, through studying the relationship between wheat quality and steamed bread in Heilongjiang province. 33 wheat varieties were used to analyze the effect of HMW-GS on the quality of steamed bread, and the results showed that HMW-GS mainly influenced the volume and whiteness of steamed bread (Zhang et al., 2015). Investigations on steamed bread quality and the HMW-GS have shown that Glu-1Ax1 and Glu-1Dx2 were positively associated with the volume of steamed bread, Glu-1Bx7 and Glu-1By8 were only positively associated with the score, and Glu-1Dx5 + 1Dy10, Glu-1By9 and Glu-1Dy12 were positively associated with both the score and volume of steamed bread (Deng et al., 2007). The subunits of $1 \mathrm{Bx} 13+1 \mathrm{By} 16$ were beneficial to steamed bread processing because of its positive association with subsidence volume and farinograph stability (Li et al., 2009).

Many previous reports have shown that most leading wheat cultivars in China are not suitable for mechanically processed food because of their weak gluten content (He, 1999; He et al., 2004; Wan et al., 1989; Wang et al., 1989; Zhang et al., 2007). In wheat cultivars, the richest variations are AxNull (66\%), 1Bx7 + 1By8 (54\%) and $1 \mathrm{Dx} 2+1 \mathrm{Dy} 12(80 \%)$, however, the high-quality subunits $1 \mathrm{Dx} 5+1 \mathrm{Dy} 10$ or $1 \mathrm{Ax} 2 *$ rarely appear (Vaiciulyte-Funk et al., 2015). Thus, increasing gluten strength to meet the quality need of wheat products, such as steamed bread and noodles, should be the direction of wheat quality improvement in future.

\section{The Molecular Markers Used for Wheat Quality Breeding}

With the improvement of our living standard, the demand for high-quality wheat is increasing. Wheat cultivars lack high-quality subunits or combination in China, such as $1 \mathrm{Dx} 5+1 \mathrm{Dy} 10,1 \mathrm{Ax} 2 *$ and $1 \mathrm{Bx} 17+1 \mathrm{By} 18$, which limit the progress of wheat quality breeding (He et al., 2003). Molecular marker assisted selection combined with conventionality breeding are regarded as a useful tool for the improvement of wheat quality.

SDS-PAGE is usually considered an efficient method for profiling gluten, but some different subunits with similar molecular weight were not differentiated readily (Lafiandra et al., 1994). For example, 1Bx7 and 1Bx7*, only a little difference in electrophoretic mobility, cannot be easily resolved by their elution time (Marchylo et al., 1992; Ragupathy, 2008). The molecular marker could distinguish the identical molecular-weight clearly. According to the sequence of Glu-1Dy10 and Glu-1Dy12, Smith et al. (1994) designed the specific primer and generated DNA marker. Butow et al. (2003) designed the PCR marker to discriminate the two types of Glu-1Bx7, and it created the opportunity for quality characteristics. Meanwhile, $1 \mathrm{Bx} 7^{\mathrm{OE}}$ was designed as the marker due to its contribution to dough strength (Butow et al. 2003). Subsequently, the specific molecular markers for the subunits of $1 \mathrm{Ax} 2 *, 1 \mathrm{Axl}, 1 \mathrm{AxNull}, 1 \mathrm{Dx} 5,1 \mathrm{Dy} 10,1 \mathrm{Dx} 2,1 \mathrm{Dyl} 2,1 \mathrm{Bx} 7,1 \mathrm{Bx} 7 *, 1 \mathrm{Bx} 17,1 \mathrm{By} 8,1 \mathrm{By} 9$ and $1 \mathrm{By} 16$ were designed (Ahmad, 2000; Debustos et al., 2001; Lei, 2006). Xu et al. (2006) analyzed the composition and distribution of HMW-GS in China by 250 wheat varieties and 175 RILs, and identified the specific marker for high-quality $1 \mathrm{Bx} 14+1 \mathrm{By} 15$ and codominant marker for $1 \mathrm{Bx} 17+1 \mathrm{By} 18$. Some major and stable QTLs of gluten strength were found on chromosomes $1 \mathrm{~A}$ and $1 \mathrm{~B}$, and several candidate markers assisted with durum wheat quality improvement through molecular breeding were identified (Johnson et al., 2013). Zhen et al. (2014) developed a specific PCR marker for Glu- $A 3 a$ allele and validate it using NILs and RILs, which could be used as a molecular marker for the improvement of gluten quality by marker assisted selection. A molecular marker that tightly linked with Glu-D1 double dull was developed, and this codominant molecular marker enhanced the speed of improvement for better biscuit making quality (Ram et al., 2019). In order to study the relationship between the subunits composition of HMW-GSs and wheat germplasm resources in China, molecular marker identification was used to analyze the quality composition of HMW-GSs among 105 winter wheat variety resources, and the results displayed that the frequency distribution of different type subunits varied greatly, such as the frequency of the high-quality subunit " $1 \mathrm{Ax} 1$ " was $42.6 \%$, but "1 $\mathrm{Ax} 2 *$ " was $14.5 \%$ (Wang et al., 2016).

\section{Conclusions}

According to our summarization, extensive studies have demonstrated that the proportion and composition of gluten have important impact on dough quality. However, the HMW glutenins play one of the most important roles in the quality of steamed bread and noodles. The availability of wheat reference genome sequence 
accelerated the identification of novel glutenins, and may enable to develop efficient molecular markers for the breeding of high-quality wheat.

\section{Acknowledgements}

This work was supported by Agricultural Variety Improvement Project of Shandong Province [2019LZGC00104], State Engineering Laboratory of Wheat and Corn Fund [2018LYZWS01] and Open Project Program (CSBAAKF 2021016) of State Key Laboratory of Crop Stress Biology for Arid Areas, NWAFU, Yangling, Shaanxi, 712100, China.

\section{References}

Ahmad, M. (2000). Molecular marker-assisted selection of HMW-glutenin alleles related to wheat bread quality by PCR-generated DNA markers. Theoretical and Applied Genetics, 101, 892-896. https://doi.org/10.1007/ s001220051558

Anjum, F. M., Khan, M. R., Din, A., Saeed, M., Pasha, I., \& Arshad, M. U. (2007). Wheat gluten: high molecular weight glutenin subunits-structure, genetics, and relation to dough elasticity. Journal of Food Science, 72, R56-R63. https://doi.org/10.1111/j.1750-3841.2007.00292.x

Appelbee, M. J., Mekuria, G. T., Nagasandra, V., Bonneau, J. P., Eagles H. A., Eastwood, R. F., \& Mather, D. E. (2009). Novel allelic variants encoded at the Glu-D3 locus in bread wheat. Journal of Cereal Science, 49(2), 254-261. https://doi.org/10.1016/j.jcs.2008.10.011

Butow, B. J., Ma, W., Gale, K. R., Cornish, G. B., Rampling, L., Larroque, O., ... Békés, F. (2003). Molecular discrimination of $\mathrm{Bx} 7$ alleles demonstrates that a highly expressed high-molecular-weight glutenin allele has a major impact on wheat flour dough strength. Theoretical and Applied Genetics, 107(8), 1524-1532. https://doi.org/10.1007/s00122-003-1396-8

Chen, Q., Zhang, W. J., Gao, Y. J., Yang, C. F., Gao, X., Peng, H. R., ... Yao, Y. Y. (2019). High Molecular Weight Glutenin Subunits 1Bx7 and 1By9 Encoded by Glu-B1 Locus Affect Wheat Dough Properties and Sponge Cake Quality. Journal of Agricultural and Food Chemistry, 67(42), 11796-11804. https://doi.org/ 10.1021/acs.jafc.9b05030

Cherdouh, A., Khelifi, D., Carrillo, J. M., \& Nieto-Taladriz, M. T. (2010). The high and low molecular weight glutenin subunit polymorphism of Algerian durum wheat landraces and old cultivars. Plant Breeding, 124(4), 338-342. https://doi.org/10.1111/j.1439-0523.2005.01118.x

Clarke, B. C., Phongkham, T., Gianibelli, M., Beasley, H., \& Bekes, F. (2003). The characterisation and mapping of a family of LMW-gliadin genes: Effects on dough properties and bread volume. Theoretical and Applied Genetics, 106, 629-635. https://doi.org/10.1007/s00122-002-1091-1

Cloutier, S., Rampitsch, C., Penner, G. A., \& Lukow, O. M. (2001). Cloning and Expression of a LMW-i Glutenin Gene. Journal of Cereal Science, 33(2), 143-154. https://doi.org/10.1006/jcrs.2000.0359

Cornish, G. B., Skylas, D. J., Siriamornpun, S., Békés, F., Larroque, O. R., Wrigley, C. W., \& Wootton, M. (2001). Grain proteins as markers of genetic traits in wheat. Australian Journal of Agricultural Research, 52(12), 1161-1171. https://doi.org/10.1071/AR01054

Debustos, A., Rubio, P., Soler, C., García, P., \& Jouve, N. (2001). Marker assisted selection to improve HMW-glutenins in wheat. Wheat in a Global Environment, 171-176. https://doi.org/10.1007/978-94-0173674-9_19

Deng, Z., Tian, J., Zhang, Y., \& Sun, C. (2007). Effects of Genotype and Environment on HMW-GS Expression and its Relationship with Steamed Bun and Bread-Baking Quality. Agricultural Journal, 2(6), 702-708.

Deng, Z. Y., Tian, J. C., \& Hu, R. B. (2006). Effects of genotype and environment on wheat main quality characteristics. Acta Ecologica Sinica, 26(8), 2757-2763.

Dong, L. L., Zhang, X. F., Liu, D. C., Fan, H. J., Sun, J. Z., Zhang, Z. J., ... Ling, H. Q. (2010). New insights into the organization, recombination, expression and functional mechanism of low molecular weight glutenin subunit genes in bread wheat. Plos One, 5, e13548. https://doi.org/10.1371/journal.pone.0013548

Dong, Z. Y., Yang, Y. S., Li, Y. W., Zhang, K. P., Lou, H. J., An, X. L., ... Wang, D. W. (2013). Haplotype variation of Glu-D1 locus and the origin of Glu-D1d allele conferring superior end-use qualities in common wheat. Plos One, 8, e7485. https://doi.org/10.1371/journal.pone.0074859 
Du, X. Y., Wei, J. L., Luo, X., Liu, Z. G., Qian, Y. Q., Zhu, B., ... Tang, H. (2020). Low-molecular-weight glutenin subunit LMW-N13 improves dough quality of transgenic wheat. Food Chemistry, 327, 127048. https://doi.org/10.1016/j.foodchem.2020.127048

FAO. (2017). FAOStat Data. Retrieved from http://faostat.fao.org

Feng, B., An, X., Xu, Z., Liu, D., Zhang, A., Wu, N., \& Wang, T. (2011). Molecular cloning of a novel chimeric HMW glutenin subunit gene 1Dx5' from a common wheat line W958. Molecular Breeding, 28(2), 163-170. https://doi.org/10.1007/s11032-010-9470-9

Galili, G., \& Feldman, M. (1985). Genetic control of endosperm proteins in wheat: 3. Allocation to chromosomes and differential expression of high molecular weight glutenin and gliadin genes in intervarietal substitution lines of common wheat. Theoretical and Applied Genetics, 69, 583-589. https://doi.org/10.1007/BF00251108

Gao, X., \& Li, S. (2002). Analysis on effect of high molecular weight glutenin subunits on industrial quality of wheat. Acta Botanica Boreali-Occidentalia Sinica, 22(4), 771-779.

Gao, Y. J., An, K. X., Guo, W. W., Chen, Y. M., Zhang, R. J., Zhang, X., ... Sun, Q. X. (2021). The endosperm-specific transcription factor TaNAC019 regulates glutenin and starch accumulation and its elite allele improves wheat grain quality. The Plant Cell, 33(3), 1-38. https://doi.org/10.1093/plcell/koaa040

Gupta, R. B., \& MacRitchie, F. (1994). Allelic variation at glutenin subunit and gliadin loci, Glu-1, Glu-3 and Gli-1 of common wheats. II. Biochemical basis of the allelic effects on dough properties. Journal of Cereal Science, 19(1), 19-29. https://doi.org/10.1006/jcrs.1994.1004

Gupta, R. B., Singh, N. K., \& Shepherd, K. W. (1989). The cumulative effect of allelic variation in LMW and HMW glutenin subunits on dough properties in the progeny of two bread wheats. Theoretical and Applied Genetics, 77(1), 57-64. https://doi.org/10.1007/BF00292316

Herpen, T., Cordewener, J., Klok, H., Freeman, F., America, A. H. P., Bosch, D., ... Hamer, R. J. (2008). The origin and early development of wheat glutenin particles. Journal of Cereal Science, 48, 870-877. https://doi.org/10.1016/j.jcs.2008.07.002

He, Z. H. (1999). Wheat production and quality requirements in China. In P. Williamson, P. Banks, I. Haak, J. Thompson \& A. Campbell (Eds.), Proc, 9th Assembly, Wheat Breeding Society of Australia, Toowoomba (pp. 23-28).

He, Z. H., Liu, A. H., Peña, R. J., \& Rajaram, S. (2003). Suitability of Chinese wheat cultivars for production of northern style Chinese steamed bread. Euphytica, 131(2), 155-163.

He, Z. H., Liu, L., Xia, X. C., Liu, J. J., \& Peña, R. J. (2005). Composition of HMW and LMW Glutenin Subunits and Their Effects on Dough Properties, Pan Bread, and Noodle Quality of Chinese Bread Wheats. Cereal Chemistry, 82(4), 345-350. https://doi.org/10.1094/CC-82-0345

He, Z. H., Yang, J., Zhang, Y., Quail, K. J., \& Peña, R. J. (2004). Pan bread and dry white Chinese noodle quality in Chinese winter wheats. Euphytica, 139(3), 257-267. https://doi.org/10.1007/s10681-004-3283-z

Hou, G. G., Saini, R., \& Ng, P. K. W. (2013). Relationship Between Physicochemical Properties of Wheat Flour, Wheat Protein Composition, and Textural Properties of Cooked Chinese White Salted Noodles. Cereal Chemistry, 90(5), 419-429. https://doi.org/10.1094/CCHEM-10-12-0137-R

Hu, X. G., Wu, B. H., Yan, Z. H., Wei, Y. M., \& Zheng, Y. L. (2008). Variations of high molecular weight glutenin subunit 1Ay in einkorn wheat. J Sichuan Agric Univ, 26, 393-398.

$\mathrm{Hu}$, X. Z. (2003). Swelling index of glutenin and their relationship with food processing quality (Master's thesis, Northwest Sci-Tech University of Agri-Forestry, China).

Jondiko, T. O., Alviola, N. J., Hays, D. B., Ibrahim, A., Tilley, M., \& Awika, J. M. (2012). Effect of high-molecular-weight glutenin subunit allelic composition on wheat flour tortilla quality. Cereal Chemistry, 89, 155-161. https://doi.org/10.1094/CCHEM-12-11-0152

Johnson, M., Kumar, A., Oladzad-Abbasabadi, A., Salsman, E., Aoun, M. Manthey, F. A., \& Elias, E. M. (2013). Association Mapping for 24 Traits Related to Protein Content, Gluten Strength, Color, Cooking, and Milling Quality Using Balanced and Unbalanced Data in Durum Wheat. Frontiers in Genetics, 10. https://doi.org/10.3389/fgene.2019.00717 
Kocourkova, Z., Bradova, J., Kohutova, Z., Slámová, L., \& Horčičkaka, P. (2008). Wheat breeding for the improved bread-making quality using PCR based markers of glutenins. Czech Journal of Genetics and Plant Breeding, 44, 105-113. https://doi.org/10.17221/20/2008-CJGPB

Lafiandra, D., D’Ovidio, R., \& Margiotta, B. (1994). Studies of high molecular-weight glutenin subunits and their encoding genes. In R. J. Henry \& J. A. Ronalds (Eds.), Improvement of Cereal Quality by Genetic Engineering (pp. 105-111). Springer, Boston, MA. https://doi.org/10.1007/978-1-4615-2441-0_13

Lafiandra, D., D’Ovidio, R., Porceddu, E., Margiotta, B., \& Colaprico, G. (1993). New data supporting high molecular glutenin subunit 5 as the determinant of quality differences among the Pairs $5+10$ vs, $2+12$. Journal of Cereal Science, 18(2), 197-205. https://doi.org/10.1006/jcrs.1993.1046

Lawrence, G. J., MacRitchie, F., \& Wrigley, C. W. (1988). Doug hand baking quality of wheat lines deficient in glutenin subunits controlled by the Glu-A1, Glu-B1 and Glu-D1 loci. Journal of Cereal Science, 7(2), 109-112. https://doi.org/10.1016/S0733-5210(88)80012-2

Lee, J. Y., Beom, H. R., Altenbach, S. B., Lim, S. H., Kim, Y. T., Kang, C. S., ... Ahn, S. N. (2016). Comprehensive identification of LMW-GS genes and their protein products in a common wheat variety. Functional \& Integrative Genomics, 16, 1-11. https://doi.org/10.1007/s10142-016-0482-3

Lei, Z. S., Gale, K. R., He, Z. H., Gianibelli, C., Larroque, O., Xia, X. C., ... Ma, W. (2006). Y-type gene specific markers for enhanced discrimination of high-molecular weight glutenin alleles at the GIu-B1 locus in hexaploid wheat. Cereal Science, 43, 94-10. https://doi.org/10.1016/j.jcs.2005.08.003

Liang, D., Tang, J. W., Peña, R. J., Singh, R., He, X. Y., Shen, X. Y., .. He, Z. H. (2010). Characterization of CIMMYT bread wheats for high-and low-molecular weight glutenin subunits and other quality-related genes with SDS-PAGE, RP-HPLC and molecular markers. Euphytica, 172(2), 235-250. https://doi.org/ 10.1007/s10681-009-0054-X

Liang, J., Chen, J., Wan, G. W., Wu, Y. Y., Zheng, W. Y., Zhang, W. M., \& Yao, D. N. (2015). "Wheat Blending Quality of Flour and Steamed Bread and Noodles in Strong and Weak Gluten Wheat." Acta Agricultura Boreali-Occidentalis Sinica, 24(5), 34-40.

Lin, J. Y. (2020). The overview and recommendations of China's wheat processing research in 2018-2019. Science and Technology of Cereals, Oils and Foods, 28(3), 61-68.

Lindsay, M., \& Skerritt J. (1999). The glutenin macropolymer of wheat flour doughs:Structure-function perspectives. Trends in Food Science and Technology, 10, 247-253. https://doi.org/10.1016/S0924-2244 (00)00004-2

Liu, L., He, Z., Yan, J., Zhang, Y., Xia, X. C., \& Peña, R. J. (2005). Allelic variation at the Glu-1 and Glu-3 loci, presence of the 1B.1R translocation, and their effects on mixographic properties in Chinese bread wheats. Euphytica, 142, 197-204. https://doi.org/10.1007/s10681-005-1682-4

Liu, L., Wang, A., Appels, R., Ma, J. H., Xia, X. C., Lan, P., ... Ma, W. J. (2009). A MALDI-TOF based analysis of high molecular weight glutenin subunits for wheat breeding. Journal of Cereal Science, 50, 295-301. https://doi.org/10.1016/j.jcs.2009.05.006

Li, Y. L., Huang, C. H., Sui, X. X., Fan, Q. Q., Li, G. Y., \& Chu, X. S. (2009). Genetic variation of wheat glutenin subunits between landraces and varieties and their contributions to wheat quality improvement in China. Euphytica, 169, 159-168. https://doi.org/10.1007/s10681-009-9905-8

Luo, C., Griffin, W. B., Branlard, G., \& Mcneil, D. L. (2001). Comparison of low- and high molecular-weight wheat glutenin allele effects on flour quality. Theoretical and Applied Genetics, 102(6), 1088-1098. https://doi.org/10.1007/s001220000433

Ma, F. Y., Kim, J., Cho, E., Brown-Guedira, G., Park, C. S., \& Baik, B. K. (2019). HMW-GS composition and rye translocations of U.S. eastern soft winter wheat and their associations with protein strength. Journal of Cereal Science, 89, 102799. https://doi.org/10.1016/j.jcs.2019.102799

Ma, W., Appels, R., Bekes, F., Larroque, O., Morell, M. K., \& Gale, K. R. (2005). Genetic characterisation of dough rheological properties in a wheat doubled haploid population: Additive genetic effects and epistatic interactions. Theoretical and Applied Genetics, 111(3), 410-422. https://doi.org/10.1007/s00122-0052001-0 
Ma, W. J., Yu, Z. T., She, M. Y., Zhao, Y., \& Islam, S. (2019). Wheat gluten protein and its impacts on wheat processing quality. Frontiers of Agricultural Science and Engineering, 6(3), 279-287. https://doi.org/ 10.15302/J-FASE-2019267

Marchylo, B. A., Lukow, O. M., \& Kruger, J. E. (1992). Quantitative variation in high molecular weight glutenin subunit 7 in some Canadian wheats. Journal of Cereal Science, 15(1), 29-37. https://doi.org/10.1016/ S0733-5210(09)80054-4

Nieto-Taladriz, M., Perretant, M. R., \& Rousset, M. (1994). Effect of gliadins and HMW and LMW subunits of glutenin on dough properties in the F6 recombinant inbred lines from a bread wheat cross. Theoretical and Applied Genetics, 88, 81-88. https://doi.org/10.1007/BF00222398

Nishio, Z., Takata, K., Ito, M., Tabiki, T., Ikeda, T. M., Fujita, Y., ... Yamauchi, H. (2007). Small-scale bread-quality-test performance heritability in bread wheat: Influence of high molecular weight glutenin subunits and the 1BL.1R Stranslocation. Crop Science, 47, 1451-1458. https://doi.org/10.2135/cropsci 2006.07.0459

Park, C. S., Kang, C. S., Jeung, J. U., \& Woo, S. H. (2011). Influence of allelic variations in glutenin on the quality of pan bread and white salted noodles made from Korean wheat cultivars. Euphytica, 180(2), 235-250. https://doi.org/10.1007/s10681-011-0385-2

Patil, V. R., Talati, J. G., Singh, C., Parekh, V. B., \& Jadeja, G. C. (2015). Genetic Variation in Glutenin Protein Composition of Aestivum and Durum Wheat Cultivars and Its Relationship with Dough Quality. International Journal of Food Properties, 18(9-12), 2393-2408. https://doi.org/10.1080/10942912. 2014.980948

Payne, E. N. I. (1987). Wheat storage proteins: Diversity of HMW glutenin subunits in wild emmer from Israel. Theoretical and Applied Genetics, 74(6), 827-836. https://doi.org/10.1007/BF00247564

Payne, P. I., Holt, L. M., \& Law, C. N. (1981). Structural and genetical studies on the high-molecular-weight subunits of wheat glutenin. Theoretical and Applied Genetics, 60(4), 229-236. https://doi.org/10.1007/ BF02342544

Ragupathy, R., Naeem, H. A., Reimer, E., Lukow, O. M., Sapirstein, H. D., \& Cloutier, S. (2008). Evolutionary origin of the segmental duplication encompassing the wheat glu-b1 locus encoding the overexpressed bx 7 (bx7oe) high molecular weight glutenin subunit. Theoretical and Applied Genetics, 116(2), 283-296. https://doi.org/10.1007/s00122-007-0666-2

Rasheed, A., Xia, X. C., Yan, Y. M., Appels, R., Mahmood, T., \& He, Z. H. (2014). Wheat seed storage proteins: Advances in molecular genetics, diversity and breeding applications. Journal Cereal Science, 60, 11-24. https://doi.org/10.1016/j.jcs.2014.01.020

Ram, S., Bhatia, V., \& Jain, V. (2006). Characterization of Low Molecular Weight Glutenin Subunit Gene Representing Glu-B3 Locus of Indian Wheat Variety $\mathrm{NP}_{4}$. Journal of Plant Biochemistry \& Biotechnology, 15(2), 79-83. https://doi.org/10.1007/BF03321908

Ram, S., Devi, R., Singh, R. B., Narwal, S., Singh, B., \& Singh, G. P. (2019). Identification of codominant marker linked with Glu-D1 double null and its utilization in improving wheat for biscuit making quality. Journal of Cereal Science, 90, 102853. https://doi.org/10.1016/j.jcs.2019.102853

Rogers, W. J., Miller, T. E., Payne, P. I., Seekings, J. A., Sayers, E. J., Holt, L. M., \& Law, C. N. (1997). Introduction to bread wheat (Triticum aestivum L.) and assessment for bread-making quality of alleles from T. boeoticum Boiss. ssp. thaoudar at Glu-Al encoding two high-molecular-weight subunits of glutenin. Euphytica, 93, 19-29. https://doi.org/10.1023/A:1002991206350

Shewry, P. R., \& Halford, N. G. (2002). Cereal seed storage proteins: Structures, properties and role in grain utilization. Journal of Experimental Botany, 53, 947-958. https://doi.org/10.1093/jexbot/53.370.947

Smith, R. L., Schweder, M. E., \& Barnett, R. D. (1994). Identification of Glutenin Alleles in Wheat and Triticale Using PCR-Generated DNA Markers. Crop Science, 34(5), 1373-1378. https://doi.org/10.2135/cropsci1994. 0011183X003400050042x

Tang, Y. L., Yang, W. Y., Tian, J. C., Li, J., \& Chen, F. (2008). Effect of HMW-GS $6+8$ and $1.5+10$ from Synthetic Hexaploid Wheat on Wheat Quality Traits. Agricultural Sciences in China, 41(11), 3465-3746. https://doi.org/10.1016/S1671-2927(08)60160-1 
Tang, Y. L., Yang, W. Y., Wu, Y. Q., Li, C. S., Li, J., Zou, Y. C., .. Mares, D. (2010). Effect of high-molecular-weight glutenin allele, Glu-B1d, from synthetic hexaploid wheat on wheat quality parameters and dry, white Chinese noodle-making quality. Crop and Pasture Science, 61(4), 310-320. https://doi.org/10.1071/CP09362

Tilley, K. A., Benjamin, R. E., Bagorogoza, K. E., Okot-Kotber, B. M., Prakash, O., \& Kwen, H. (2001). Tyrosine cross-links: Molecular basis of gluten structure and function. Journal of Agricultural and Food Chemistry, 49(5), 2627-2632. https://doi.org/10.1021/jf010113h

Vaiciulyte-Funk, L., Juodeikiene, G., \& Bartkiene, E. (2015). The relationship between wheat baking properties, specific high molecular weight glutenin components and characteristics of varieties. Zemdirbyste, 102(2), 229-238. https://doi.org/10.13080/z-a.2015.102.030

Wan, F. S., Wang, G. R., \& Li, Z. Z. (1989). A preliminary approach onpresent situation and objectives of improvement of wheat quality in China. Scientia Agricultura Sinica, 22(3), 14-21.

Wang, D. W., Li, F., Cao, S. H., \& Zhang, K. P. (2020). Genomic and functional genomics analyses of gluten proteins and prospect for simultaneous improvement of end-use and health-related traits in wheat. Theoretical and Applied Genetics, 133(5), 1521-1539. https://doi.org/10.1007/s00122-020-03557-5

Wang, L. J., Wang, C. Y., Sun, D., Wang, Y. M., Li, P. L., Guo, H. X., ... Zhang, L. G. (2016). HMW-GS composition analysis of winter wheat germplasm from China with molecular markers. The 7th International Crop Science Congre, 46(001), 121-129.

Wang, Q. R., Lin, X. M., Zeng, Z. R., \& Zhuang, Q. S. (1989). Bread making quality of major Chinese wheat cultivars, Institute of Crop Breeding and Cultivation, CAAS. Wheats Journal Cereal Science, 5, 29-37.

Wang, X. L., Zhang, Y. Q., Zhang, B., Florides, C. G., Gao, Z., Wang, Z. H., ... Wei, Y. M. (2018). Comparison of quality properties between high-molecular-weight glutenin subunits $5+10$ and $2+12$ near-isogenic lines under three common wheat genetic backgrounds. Cereal Chemistry, 95(4), 575-583. https://doi.org/ $10.1002 /$ cche. 10061

Xiang, J. S., Mu, P. Y., Sang, W., Xu, H. J., Nie, Y. B., Zhuang, L., ... Zou, B. (2015). Effect of Allelic Variation in HMW/LMW-GS on Processing Quality of Xinjiang Hand-Stretched Noodles and Protein Traits of Wheat. Journal of Triticeae Crops.

Xu, L. L., Li, W., Wei, Y. M., \& Zheng, Y. L. (2009). Genetic diversity of HMW glutenin subunits in diploid, tetraploid and hexaploidy Triticum species. Genet Resour Crop Evol, 56, 377-391. https://doi.org/ 10.1007/s10722-008-9373-3

Xu, Q., Xu, J., Liu, C. L., Chang, C., Wang, C. P., You, M. S., ... Liu, G. T. (2008). PCR-based markers for identification of HMW-GS at Glu-B1x loci in common wheat. Journal of Cereal Science, 47(3), 394-398. https://doi.org/10.1016/j.jcs.2007.05.002

Xu, T., Zhang, X. Y., \& Dong, Y. S. (2006). Expression Analysis of HMW-GS 1Bx14 and 1By15 in Wheat Varieties and Transgenic Research of 1By15 Gene. Agricultural Sciences in China, 5(010), 725-735. https://doi.org/10.1016/S1671-2927(06)60117-X

Yanaka, M., Takata, K., Ikeda, T. M., \& Ishikawa, N. (2007). Effect of the High-Molecular-Weight Glutenin Allele, Glu-D1d, on Noodle Quality of Common Wheat. Breeding Science, 57(3), 243-248. https://doi.org/10.1270/jsbbs.57.243

Yan, R., Wang, T., Xu, Z. B., Yang, Z. J., \& Ren, Z. L. (2008). Molecular characterization of a novel HMW-GS 1Dx5' associated with good bread making quality (Triticum aestivum L.) and the study of its unique inheritance. Genetic Resources \& Crop Evolution, 55, 585-592. https://doi.org/10.1007/s10722-007-9262-1

Yang, F. P., \& Wang, S. R. (2003). Relationship between the Subunits of High Molecular Weight Gluten and Quality Characters of Wheat. Journal of Triticeae Crops, 23(4), 32-35.

Zhang, P. P., He, Z. H., Zhang, Y., Xia, X. C., Liu, J. J., Yan, J., \& Zhang, Y. (2007). Pan Bread and Chinese White Salted Noodle Qualities of Chinese Winter Wheat Cultivars and Their Relationship with Gluten Protein Fractions. Cereal Chemistry, 84(4), 370-378. https://doi.org/10.1094/CCHEM-84-4-0370

Zhang, P., Jondiko, T. O., Tilley, M., \& Awika, J. M. (2015). Effect of high molecular weight glutenin subunit composition in common wheat on dough properties and steamed bread quality. Journal of the Science of Food and Agriculture, 94(13), 2801. https://doi.org/10.1002/jsfa.6635 
Zhang, X. F., Jin, H., Zhang, Y., Liu, D. C., Li, G. Y., Xia, X. C., ... Zhang, A. M. (2012). Composition and functional analysis of low-molecular weight glutenin alleles with Aroona near-isogenic lines of bread wheat. BMC Plant Biology, 12, 243. https://doi.org/10.1186/1471-2229-12-243

Zhang, Y. Q., Wei, Y. M., Zhang, B., Zhang, X. K., Dong, K. N., \& Liu, R. (2013). Influence of High Molecular Weight Glutenin Subunits (HMW-GS) on Sensory Quality Properties of Chinese Dry Noodle. Scientia Agricultura Sinica, 46(1), 121-129.

Zhao, L. Y., Li, L. Q., Song, L. J., Liu, Z. Z., Li, X., \& Li, X. J. (2020). HMW-GS at Glu-B1 Locus Affects Gluten Quality Possibly Regulated by the Expression of Nitrogen Metabolism Enzymes and Glutenin-Related Genes in Wheat. Journal of Agricultural and Food Chemistry, 68, 5426-5436. https://doi.org/10.1021/acs.jafc.0c00820

Zhao, N. X. (1995). Studies on the Relationship between Wheat Flour with Different Gluten Content and Quality of Steamed Bread in Heilongjiang Province. Cereal Quality Analysis Center of Heilongjiang Academy of Agricultural Sciences.

Zhen, S. M., Han, C. X., Ma, C. Y., Gu, A. Q., Zhang, M., Shen, X. X., ... Yan, Y. M. (2014). Deletion of the low-molecular-weight glutenin subunit allele Glu-A3a of wheat (Triticum aestivum L.) significantly reduces dough strength and breadmaking quality. BMC Plant Biology, 14(1), 367. https://doi.org/10.1186/s12870-014-0367-3

Zhou, Y., Cao, H., Hou, M., Nirasawa, S., Tatsumi, E., Foster, T. J., \& Cheng, Y. (2013). Effect of konjac glucomannan on physical and sensory properties of noodles made from low-protein wheat flour. Food Research International, 51(2), 879-885. https://doi.org/10.1016/j.foodres.2013.02.002

\section{Copyrights}

Copyright for this article is retained by the author(s), with first publication rights granted to the journal.

This is an open-access article distributed under the terms and conditions of the Creative Commons Attribution license (http://creativecommons.org/licenses/by/4.0/). 